\title{
Research on the Relationship between Chinese Marine Economy Growth and Investment in Marine Technology
}

\author{
Liangyu Zhao \\ Business school of shanghai university in China \\ hirygirl@163.com
}

Keywords: Investment in marine technology; Marine economy growth; Contribution

\begin{abstract}
Increase in the investment in marine science and technology can effectively promote the development of marine science and technology and industrialization. Based on the existing literature, this paper measured the relationship between marine economy growth and investment in marine technology through an expanded model of the Cobb-Douglas production function, using the annual data from 2005 to 2013.The results show that China's marine economy was typically capital-driven, and development in marine technology makes inadequate contribution to marine economy growth.
\end{abstract}

\section{Introduction}

Since the reform and opening up, China's has made great achievements in marine industry. Meanwhile, the proportion of marine economy in the national economy is increasing from $1.9 \%$ in 1996 to $9.6 \%$ in 2015, as marine economy has become a new economic growth point in China. During the period from 1986 to 2000, the number of National Science Foundation funded marine projects was 602 and the amount of subsidy was 89.185 million yuan, while the amount of subsidy in 1982 was only 510,000 yuan [1].Along with marine economic development, China's investment in marine science and technology is also increasing rapidly. This paper will use empirical research methods to study the relationship between investment in marine technology and development of marine economy.

\section{Literature Review}

Foreign scholars has always been interested in the relationship between investment in science and technology and economic development .According to Gary S. Becker(1992), the comparison between the technological investment's share of GDP in developed countries show that there is a close relationship between science and technology investment and economic growth [2]. Jones Charles (1998) use the data of 10 major developed countries and draw the conclusion that R \& D is an important source of total factor productivity growth [3].

Domestic research on the quantitative relationship between investment in marine science and technology and marine economy growth is relatively less. Zhong Hua (2008) conducted gray system analysis about the relationship between marine science and technology investment and marine economic growth, concluding that the marine science and technology funding and professional personnel have positive correlation with marine economy growth[4].Yin Kedong (2009) use evaluation index system to measure the level of marine science and marine economy and evaluate the relationship between marine technology and marine economy through coordinate development model [5].

\section{Model and Data}

Selection of Model. First we select Cobb-Douglas production function as the theoretical basis of this study, and then we make some change. Take the investment of technology as another input, the C-D production function can be written as follows: 


$$
Y(t)=f(K, L)=A\left(K_{1}^{\beta} K_{2}^{1-\beta}\right)^{\alpha} L^{1-\alpha}
$$

In this model, $\mathrm{Y}$ represents output, $\mathrm{K}$ represents capital, $\mathrm{L}$ represents labor. Capital investment is used for two purposes: First, producing the final product; second, providing intermediate inputs for the final product-scientific and technological achievements. $\mathrm{K}_{1}$ and $\mathrm{K}_{2}$ respectively represent the amount of fixed capital investment and investment in science and technology. Take the logarithm on both sides of (1):

$$
\ln Y(t)=\ln A(t)+\alpha(1-\beta) \ln K_{1}(t)+(1-\alpha) \ln L(t)
$$

Specific econometric model is as follows:

$$
\ln Y_{i t}=a+b_{1} \ln K_{i t}+b_{2} \ln T_{i t}+b_{3} \ln L_{i t}+\varepsilon_{i t}
$$

In this model, $\ln Y_{i t}$ represents the natural logarithm of marine economic output (GDP) in the coastal areas $i$, which is the dependent variable of the model. $\ln K_{i t}$ is the natural logarithm of investment in fixed assets of areas $I$ in year $t$, representing a capital investment of marine economic situation. $\operatorname{lnL} \mathrm{L}_{\text {it }}$ means the natural logarithm of the number of marine industry practitioners in region $\mathrm{i} . \ln \mathrm{T}_{\mathrm{it}}$ stands for the natural logarithm of the amount of investment in marine science and technology of area i, reflecting the level of marine science and technology funding. In general, higher level of the direct financial investment in marine science and technology would make more promotion to the marine growth. Therefore, we expect the sign of the model regression coefficients are positive

Data Description. This paper selects panel data from 2005 to 2013 of China's 11 coastal provinces, municipalities and autonomous regions [6]. Considering that price factor would make data incomparable, so we convert the outputs and fixed capital inputs based on the year 2005, ensuring the authenticity of the estimation model.

We take the gross ocean product (GDP) as a measure of the output of the ocean; Based on the study of Zhai Renxiang [7], we estimate the investment in fixed assets by the perpetual inventory method as follows:

$$
\mathrm{K}_{\mathrm{t}}=\mathrm{K}_{\mathrm{t}-1}\left(\theta_{\mathrm{t}}\right)+\mathrm{h}_{\mathrm{t}}
$$

In this equation, $K_{t}$ is the marine capital stock in the year $t ; K_{t-1}$ is the marine capital stock in the year $t-1 ; \theta_{t}$ stands for the marine capital depreciation rate in the year $t ; h_{t}$ means the amount (flow) of investment in marine fixed assets in the year t. Under China's current economic and technological system, these marine science and technology activities are mainly undertaken by marine research institutes [7], so we choose the financial income of marine research institutions as quantitative indicators of investment in marine science and technology; we select sea-related employment as a maritime labor measure.

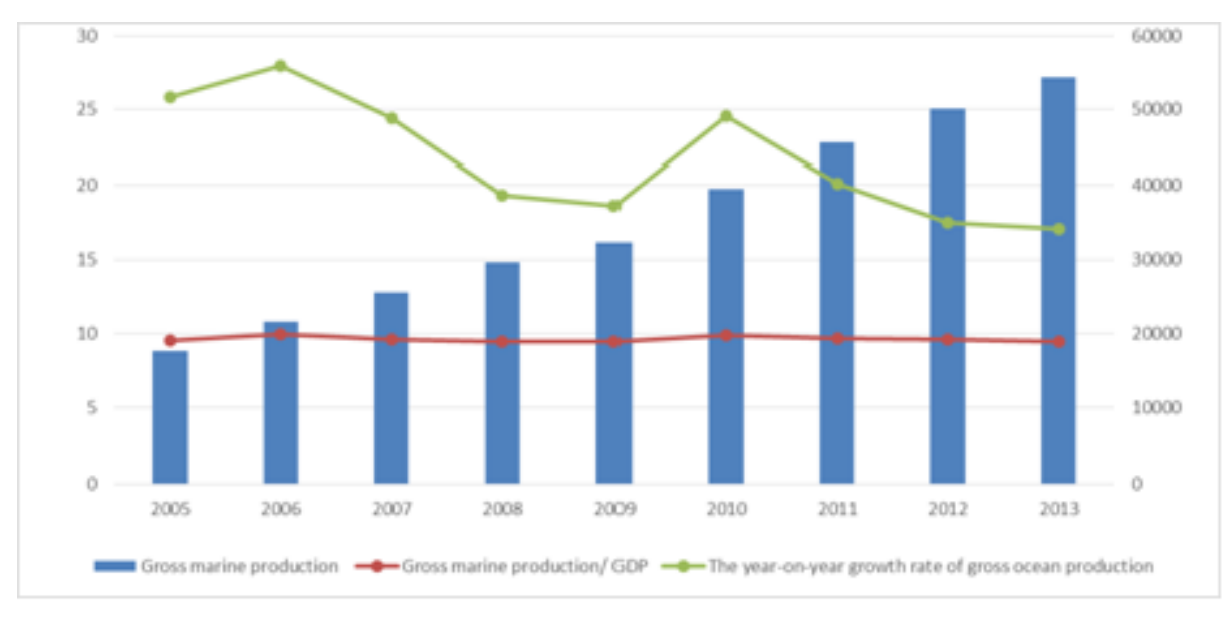

Figure 1. Marine Industry Growth in China 


\section{Empirical Analysis}

We use the Stata12.0 to graph the relationship between marine science investment and marine output. From the Fig. 2, we can see that marine science investment has a strong positive correlation with marine output.

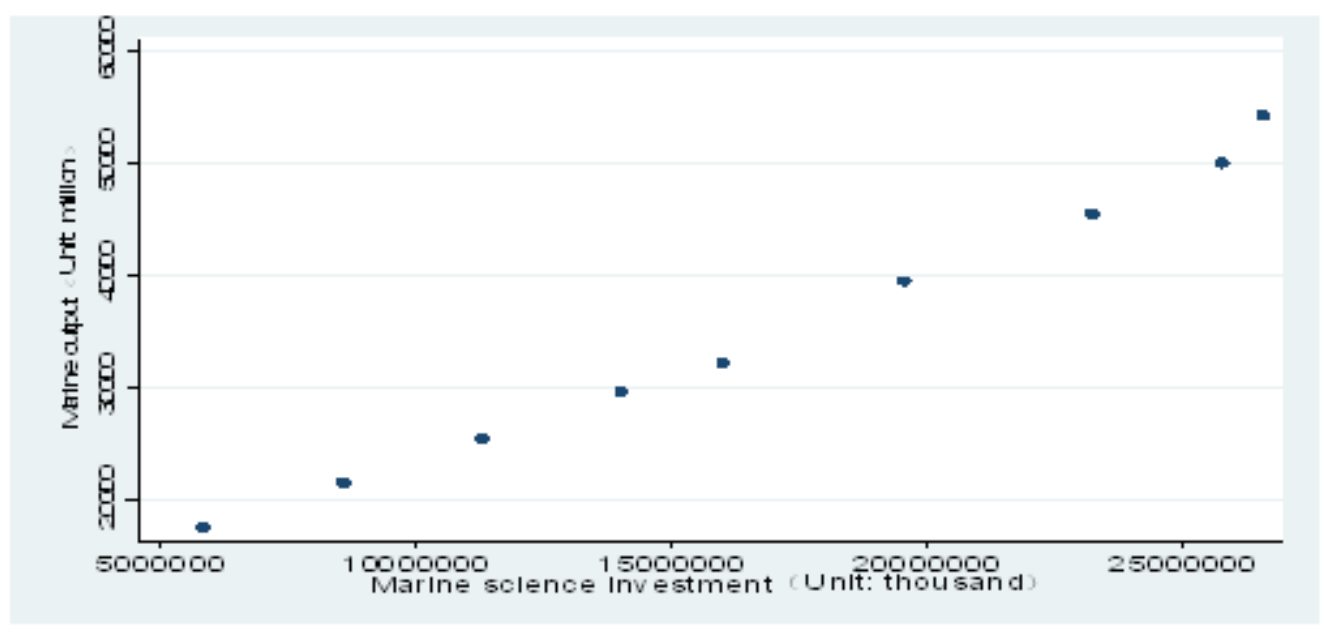

Figure 2. Scatter plot between marine science investment and marine output

After estimation, the relationship equation of maritime economic development and the elements (capital, technology, labor) can be written as follows:

$$
\ln Y_{i t}=1.642+(0.768) \ln K_{i t}+(0.162) \ln T_{i t}+(0.076) \ln L_{i t}
$$

Regression analysis showed that the elasticity coefficient of fixed asset investment, science and technology investment and labor are positive, consistent with the initial forecast, and each of them is significant at $1 \%$ significance level. From this equation, we can see that the elasticity coefficient of investment in fixed assets is the biggest, 0.768 ; second is the elasticity coefficient of science and technology investment, 0.162 ; the elasticity coefficient of labor is the least, less than 0.1.From this we can see that the marine industry's capital make the greatest contribution to marine economic growth and marine economic growth is heavily dependent on industry capital. The contribution of marine scientific and technological to the development of marine economy is relatively significant.

\section{Conclusions}

After entering the new century, the status of marine economy in China's economy has become increasingly important in recent years, the gross economic output of marine production accounted for around 9\% in Chinese GDP. Also, development of marine economy has become one of the most important parts in coastal areas of region's economic development.

This paper makes empirical analysis about the contribution of investment in marine science and technology in coastal areas to marine economic growth, using the data from 2005 to 2013. Conclusions are as follows:

Fixed assets investment in coastal regions has a significant positive role in promoting marine economic growth. When the investment in fixed assets increase by $1 \%$, the marine economy would be increased by around $0.77 \%$; labor force growth has a weak positive correlation with marine economic growth. When the labor input increase by $1 \%$, the marine economy would be increased by around $0.076 \%$. This shows that China's marine economy growth was investment-driven. This paper focus on the influences made by marine science and technology investment on marine economic growth. The results show that each $1 \%$ increase in the marine science and technology investment can. 
Promote marine economy to increase by $0.16 \%$, which is twice as positive as labor input element.

To make a concrete analysis, there are two main reasons contributing for the weak influences on the marine economic growth of marine science and technology investment:

First of all, the majority of China's marine industries are labor-intensive, such as marine fisheries, marine shipping industry and etc. These industries can provide work for a large number of people and solve the problem of employment, but they are not sensitive to technology investment. Nowadays, marine science and technology investment are mainly focused on these industries and therefore marine science and technology make little contribution to marine economic growth.

Secondly, China's investment in marine science and technology are primarily aimed at universities and research institutions. Although the levels and the number of marine science and technology achievements have been enhanced, the conversion rate of marine scientific and technological achievements is not high because of imperfect market mechanisms of marine science and technology achievements trade. That is to say, the marine scientific and technological achievements are only potential productivity and

The influence of these achievements on the turnover into real productivity has time-lag effect.

It is the fundamental objective that marine science and technology investment could promote sustainable marine economic growth and development in marine society. The government should increase investment in marine science and technology and take the key areas of marine science and technology into consideration; combine the marine science and technology investment with the upgrade and optimization of ocean industrial structure; make good guide for diversified investment to increase output of marine science and technology and the promotion of marine scientific and technological achievements conversion. Only in this way, can the marine science and technology investment play more positive effect on the marine economic growth and provide intellectual support for the sustainable development of marine economy.

\section{References}

[1] Wang Hui. 15 years retrospect and prospect on Marine scientific research [J]. Advances in Earth Science, 2001, 16 (6): 871.

[2] Gary Becker Murply. The division labor, coordination cost and knowledge [J]. Quarterly Journal of Economics, 1992(107):1137-1160.

[3] Jones Charles. Growth: with or without scale effect [J]. American Economic Review, 1998, 89: 139-144.

[4] Zhong Hua, Zhao Xin. Grey correlation analysis of science and technology investment and economic growth [J]. Ocean Information, 2008 (2): 21-23.

[5] Yin Kedong, Wang Wei, Feng Xiaobo. Research on the coordinate relationship between marine technology and marine economy development [J]. Ocean Development and Management, 2009, 26 (2): 107-112.

[6] "China Ocean Yearbooks" editorial. China Marine Statistical Yearbook (2005-2013) [M]. Beijing: Ocean Press.

[7] Zhai Renxiang. Marine science and technology investment and marine economic growth [J]. Practice and Theory in Mathematics, 2014 (2): 75-80.

[8] Solow R. Technical Change and the Aggregate Production Function [J] .Review of Economics and Statistics, 1957 (39): 312-320.

[9] Ma Xiuzhen, Mao Zhenpeng. An Empirical Study on the relationship between marine science and technology investment and economic development in Shandong province [J]. Journal of Qingdao University of Science \& Technology (SOCIAL SCIENCE EDITION), 2015, 02:68-70.- 
[10] Qiao Junguo, Zhu Jianzhen. Governmental marine science and technology investment and marine economic growth: An Empirical Study Based on panel data [J]. Science and Technology Management Research, 2012, 04:37-40.

[11] Zhu Liming. Discussion on coordinate development of science and technology and economy [J].Science and Technology Management Research, 1994, 04:1-5.

[12] Zhang Renkai, Yang Yaowu. The research and evaluation on the coordinate situation between the progress of science and technology and economic development in China [J]. World Science Research and Development, 2007, 01:100-106. 